\title{
Observed (1970-1999) climate variability in Central America using a high-resolution meteorological dataset with implication to climate change studies
}

\author{
H.G. Hidalgo ${ }^{1,2}$ • E.J. Alfaro ${ }^{1,2,3}$ • \\ B. Quesada-Montano ${ }^{2,4}$
}

Received: 25 August 2015 / Accepted: 26 August 2016/Published online: 24 October 2016

(C) The Author(s) 2016. This article is published with open access at Springerlink.com

\begin{abstract}
High spatial resolution of precipitation (P) and average air temperature (Tavg) datasets are ideal for determining the spatial patterns associated with large-scale atmospheric and oceanic indexes, and climate change and variability studies, however such datasets are not usually available. Those datasets are particularly important for Central America because they allow the conception of climate variability and climate change studies in a region of high climatic heterogeneity and at the same time aid the decisionmaking process at the local scale (municipalities and districts). Tavg data from stations and complementary gridded datasets at $50 \mathrm{~km}$ resolution were used to generate a high-resolution $(5 \mathrm{~km}$ grid) dataset for Central America from 1970 to 1999. A highresolution P dataset was used along with the new Tavg dataset to study climate variability and a climate change application. Consistently with other studies, it was found that the 1970-1999 trends in P are generally non-significant, with the exception of a few small locations. In the case of Tavg, there were significant warming trends in most of Central America, and cooling trends in Honduras and northern Panama. When the sea surface temperature anomalies between the Tropical Pacific and the Tropical Atlantic have different (same) sign, they are a good indicator of the sign of P (Tavg)
\end{abstract}

This article is part of a Special Issue on "Climate change impacts on ecosystems, agriculture and smallholder farmers in Central America" edited by Camila I. Donatti and Lee Hannah.

Electronic supplementary material The online version of this article (doi:10.1007/s10584-016-1786-y) contains supplementary material, which is available to authorized users.

H.G. Hidalgo

hugo.hidalgo@ucr.ac.cr

1 School of Physics, University of Costa Rica, San Pedro 2060, Costa Rica

2 Center for Geophysical Research, University of Costa Rica, San Pedro 2060, Costa Rica

3 Center for Research in Marine Sciences and Limnology, University of Costa Rica, San Pedro 2060, Costa Rica

4 Department of Earth Sciences, Uppsala University, Villav. 16, 75236 Uppsala, Sweden 
annual anomalies. Even with non-significant trends in precipitation, the significant warming trends in Tavg in most of Central America can have severe consequences in the hydrology and water availability of the region, as the warming would bring increases in evapotranspiration, drier soils and higher aridity.

\section{Introduction}

High spatial resolution of precipitation (P) and average air temperature (Tavg) datasets are ideal for determining the spatial patterns associated with large-scale atmospheric and oceanic indexes, and for supporting climate change and variability studies. Those datasets are particularly important for Central America because they allow the conception of climate variability and climate change studies in a region of high climatic heterogeneity and at the same time aid the decision-making process at the local scale (municipalities and districts). However such datasets are not usually available.

When analyzing $\mathrm{P}$ data through time to help guide climate change adaptation efforts in Central America, there are two extra considerations that must be noted: First, given that there is no snow to be affected by temperature changes, annual $\mathrm{P}$ variations are probably the key factor that controls inter-annual hydrologic variations in Central America. However, temperature could still affect variability and especially trends on sensitive hydrological variables such as runoff and soil moisture through its influence on evapotranspiration (Imbach et al. 2012; Hidalgo et al. 2013). This is particularly true for Central America, a tropical region with high temperatures and relatively low variability throughout the year. Imbach et al. (2012) have attributed the projected drying runoff trends at the end of the century to increases in temperature that result in higher evapotranspiration losses. For this reason it is important to not only access a $\mathrm{P}$ dataset, but also a Tavg dataset in order to understand trends and model hydrological response resultant from those trends. Second, even if the trends in annual $\mathrm{P}$ are small, the distribution of rainfall at shorter time-scales could still cause significant changes in hydrological variables that would require special adaptation measures. Some studies have suggested that the frequencies of extreme (high and low) $\mathrm{P}$ events are increasing (Aguilar et al. 2005; IPCC 2007).

We present a high-resolution $(5 \mathrm{~km} \times 5 \mathrm{~km})$ monthly Tavg dataset for Central America (1970-1999) constructed using the procedures described in Daly et al. (1994, 2002, 2008), representing a modified version of the proprietary Parameter-elevation Regressions on Independent Slopes (PRISM) method. Along with a high-resolution P dataset obtained from other sources (see Data and Methods Section), the Tavg dataset were used in several climate variability analyses, including trends, connections with atmospheric and oceanic indexes, Rotated Empirical Orthogonal Functions (REOFs; e.g. Navarra and Simoncini 2010), and Canonical Correlation Analysis (CCA; Alfaro 2007a, 2007b). The high-resolution dataset was also used to produce future climate projections. These analyses could provide information to future studies regarding adaptation measures that are needed for reducing the impacts of anthropogenic climate change. Other possible uses of the Tavg dataset is for studies of detection and attribution of climate change (Barnett et al. 2008; Bonfils et al. 2008; Pierce et al. 2008; Hidalgo et al. 2009), statistical downscaling (Maurer and Hidalgo 2008; Maurer et al. 2010; Wood et al. 2004), and to determine changes in runoff in observations and projections (Hidalgo et al. 2013). 
Anthropogenic signal in certain (hydro)climatic variables has been statistically detectable above the natural variability "noise" starting from the 1980s (Meehl et al. 2007; Barnett et al. 2008). This detection has been linked to (hydro)climatic processes in mid-latitudes that are sensitive to temperature, such as Tavg, snow accumulations and timing of streamflow in snow-controlled basins (Bonfils et al. 2008; Pierce et al. 2008; Hidalgo et al. 2009). Overall, observed changes in $\mathrm{P}$ in mid-latitude regions show fewer locations with significant trends than the changes in temperature (Aguilar et al. 2005; Alexander et al. 2006). Therefore, in a region like Central America where the $P$ trends are small, the $P$ anomalies associated with natural climatic causes are the largest contribution to the variability. The contributions of natural climatic causes to the total $\mathrm{P}$ variance in the inter-annual, decadal and trend components were estimated in $84 \%, 14 \%$ and $2 \%$ in Central America respectively (Hidalgo León et al. 2015). Understanding climate variability through time is key as adapting to climate variability is a great step forward in the adaptation to climate change (Zebiak et al. 2014). Climate variability in the form of El Niño-Southern Oscillation (ENSO), for example, impacts many society's aspects such as agriculture and food security, water resources, health, disaster occurrences, and numerous other means (Zebiak et al. 2014).

Performing climate variability analysis in high resolution is especially important for Central America as this region presents many climatic contrasts due to the influence of rich topographic features, and the exposure to large-scale climatic processes. The most dominant synoptic (large scale) influence in Central America is the subtropical high of the North Atlantic (Taylor and Alfaro 2005; Hidalgo et al. 2015), associated with the easterly trade winds strength. The main large-scale processes that affect climate in the region at interannual time scales are ENSO, Caribbean and Atlantic climatic processes such as the Caribbean LowLevel Jet (CLLJ; Amador 1998, 2008) or Tropical North Atlantic (TNA; Enfield et al. 1999) climatic variations, the location of the Inter-tropical Convergence Zone (ITCZ, Hidalgo et al. 2015), the Pacific Decadal Oscillation (PDO; Mantua et al. 1997) and other features. Amador et al. $(2006,2016)$ present a more detailed review of the main controls that affect the climate in Central America.

\section{Data and methods}

\subsection{Constructing Tavg high-resolution dataset}

The spatial dataset of Tavg for 1970-1999 at $5 \mathrm{~km}$ resolution dataset was constructed using a procedure for estimating gridded meteorological patterns using a method contained in Daly et al. $(1994,2002,2008)$ in a process similar to PRISM (it should be mentioned that we do not claim that the method used here can be called PRISM, as that acronym is a reference to a particular software with different characteristics as the method proposed here). Using Tavg data from a set of weather stations and a coarse gridded Tavg dataset (listed in next section) near the point of interest that is being processed, the method performs weighted regressions between the station elevation from a Digital Elevation Model (DEM) and the value (monthly or daily) of the meteorological parameter. The weights are assigned according to several criteria referenced to the conditions of the point of interest and the stations. Originally, Daly et al. (2002) identified seven kinds of weights: distance (W(d)), elevation $(\mathrm{W}(\mathrm{z}))$, cluster $(\mathrm{W}(\mathrm{c}))$, vertical layer $(\mathrm{W}(\mathrm{l}))$, topographic facet $(\mathrm{W}(\mathrm{f}))$, coastal proximity $((\mathrm{W}(\mathrm{p}))$ 
and effective terrain (W(e)). The weights are combined into a total weight $\mathrm{W}$, in the following way (Daly et al. 2002):

$$
W=\left[F_{d} W(d)^{2}+F_{z} W(z)^{2}\right]^{\frac{1}{2}} W(c) W(l) W(f) W(p) W(e)
$$

Where $F_{d}$ and $F_{z}$ are the distance and elevation weighting importance factors (set to typical values of 0.8 and 0.2 respectively). All weights and importance factors are normalized to unity individually and combined (Daly et al. 2002). For a detailed description of the procedure used here, see Daly et al. (2002). Parameters used in the procedure are in table S1 (Supplementary Material). The names of the parameters in this table and throughout the article are consistent with Daly et al. (2002) nomenclature. The gridding model was used to produce Tavg at $5 \mathrm{~km}$ spatial resolution at monthly time scales.

\subsection{Data used}

\subsubsection{NUMEROSA}

The base station dataset used (NUMEROSA) was obtained from the Center for Geophysical Research (CIGEFI in Spanish) at the University of Costa Rica and it is a compilation of data for the period 1970-1999. There were 84 stations to compute the monthly Tavg patterns, some of them are shown in Figure S1 in the Supplementary Material (there were other stations in northern Colombia and southern Mexico that are not shown in this figure). A visual inspection was performed on the data and the procedure for filling missing gaps was performed using Alfaro and Soley (2009). The period for all datasets was set to 1970-1999 due to the considerable reduction in the number of available stations after 1999.

\subsubsection{Maurer et al. (2009) Tavg dataset}

Gridded daily and monthly Tavg data at $50 \mathrm{~km}$ resolution from Maurer et al. (2009) were used, along with NUMEROSA station data, as input to the modified PRISM model to generate the monthly Tavg datasets. The monthly Maurer et al. (2009) data are based on Climate Research Unit (CRU; Jones and Moberg 2003), and National Center of Atmospheric Research and the National Climatic Data Center (NCEP/NCAR) reanalysis data (Kalnay et al. 1996). These data were used in order to complete the information in regions where there was limited or nonexistent station data. Although there could be the possibility of some of our stations entering the reanalysis, we think that the effect of double counting is minimum, as there are only a few individual stations compared to the contribution of gridpoints. The modified PRISM method applied here incorporated the effect of terrain on the spaces in between the coarse gridded data and the stations, providing a higher resolution version $(5 \times 5 \mathrm{~km})$ of the meteorological parameters; however it should be recognized that the use of the coarse grid data as part of the input to the gridding model would probably smooth out the resulting patterns.

\subsubsection{Digital elevation model (DEM)}

The DEM used was the GTOPO30 data for Central America originally at a resolution of 5arcseconds (or approximately $140 \mathrm{~m}$ ) (Figure S1 in the Supplementary Material). The data was 
linearly interpolated to the grid of the Climate Hazards Group InfraRed Precipitation with Station data (CHIRPs) to produce a common grid. The DEM was used to obtain the necessary elevations of the grid-points for the establishment of elevation-temperature regressions used in the modified PRIM method in Section 2.1.

\subsubsection{Radiosonde data}

Daily aerological radiosonde data for 1973-2013, collected at 6 a.m. local time for the Juan Santamaria International Airport in Costa Rica (station \#78,762), were obtained from the CIGEFI's archives. These data were used to determine the typical height and frequency of inversion layer (i.e. the layer in which the temperature increases with altitude) for all months of the year. The inversion layer's height was used to determine the vertical layer weight (W(1) in Eq. (1) as it defines two layers of the atmosphere (boundary-layer and free-atmosphere) as shown in Figure S3 in the Supplementary Material. The particular value of this type of weight depends on whether or not the station is located in the same or in different layer as the gridpoint of interest (see Daly et al. 2002 for details). The average height for all days when an inversion layer occurred was $118 \mathrm{~m}$ above the elevation of the station (908 m.a.s.l.). Inversion occurred in $40 \%$ of records and it seems to have similar frequencies for all months of the year (Figure S2 in Supplementary Material).

\subsection{Climate variability analysis}

Climate variability over Central America was analyzed for the 1970-1999 period. The first part of the analyses consisted in calculating P and Tavg trends. For this calculation we used the resulting high-resolution monthly Tavg dataset from this study, along with the high-resolution monthly P dataset from CHIRPs. The CHIRPs dataset was produced at the University of California, Santa Barbara, and is a 30+ year quasi-global rainfall dataset (http://chg.geog.ucsb. edu/data/chirps/). CHIRPS incorporates $0.05^{\circ}$ resolution satellite imagery with in-situ station data to create gridded rainfall time series for trend analysis and seasonal drought monitoring. We are using the first version of the dataset since this covers the period 1970-2004 and that allowed us to have at least 30 years of data for the analyses.

The trend analysis of $\mathrm{P}$ and Tavg was also done using low-resolution $\mathrm{P}$ and Tavg datasets to assess the robustness of the results obtained with the high-resolution datasets. For temperature, those low-resolution datasets included: 1) the Climate Anomaly Monitoring System dataset (CAMS; Fan and van den Dool 2008), 2) the CRU version 2 temperature dataset (CRUTEMP2, Jones and Moberg 2003), and 3) the National Center of Environmental Prediction/National Center for Atmospheric Research (NCEP/NCAR) reanalysis (Kalnay et al. 1996). For P, 1) the NCEP/NCAR reanalysis, and 2) the Chen et al. (2002) dataset (hereinafter the CHEN dataset) were used. These data cover different periods, but all of them include the 1970-1999 period of study.

The second part was an analysis of Rotated Empirical Orthogonal Functions or REOFs and CCA. In order to decompose the variability of the $\mathrm{P}$ and Tavg into eigen-modes that allow interpreting the original datasets into compact principal modes of variability, we performed a REOF analysis. Rotation of EOFs is recommended to aid in the physical interpretation of the modes (Haan 1977). These REOFs were later associated with large-scale climatic processes such as ENSO, which allowed defining the extension of the regions associated with these climatic processes. Details of this analysis can be found in Appendix G of the Supplementary 
Material. In order to determine if there is a coupling in some parts of the region between $\mathrm{P}$ and Tavg, we performed a CCA. The CCA consists of pairs of scores representing the variability of both types of datasets used in the analysis. Those pairs are ordered from highest to lowest intercorrelation.

The third part of the climate variability analysis consisted on a correlation between the highresolution Tavg and $\mathrm{P}$ datasets with five different climate indices. These indices quantify different climate and ocean phenomena, and their correlation with Tavg and $\mathrm{P}$ is a way to assess the influence that these phenomena have on the climate of Central America. The indices used were ENSO, The Tropical North Atlantic (TNA), The Caribbean Low Level Jet (CLLJ), The Pacific Decadal Oscillation (PDO) and The Atlantic Multidecadal Oscillation (AMO). ENSO, which represents the oceanic-atmospheric conditions in the tropical Pacific, is estimated as the monthly sea surface temperature anomalies (SSTa) averaged over the region known as Niño3.4 $\left(170^{\circ} \mathrm{W}-120^{\circ} \mathrm{W}, 5^{\circ} \mathrm{S}-5^{\circ} \mathrm{N}\right)$. The data were obtained from Earth System Research Laboratory, Physical Sciences Division of the National Oceanic \& Atmospheric Administration (ESRL-PSD-NOAA) at http://www.esrl.noaa.gov/psd/data/ climateindices/list/. The TNA index, which represents the SST variability in the tropical Atlantic (Enfield et al. 1999) is calculated with monthly SSTa data averaged over the region $15^{\circ} \mathrm{W}-57.5^{\circ} \mathrm{W}, 5.5^{\circ} \mathrm{N}-23.5^{\circ} \mathrm{N}$ obtained from ESRL-PSD-NOAA. The CLLJ index (Amador 1998, 2008), which represents the strength of the Trade Winds, consists of a region of about $500 \mathrm{~km}$ in width (north-south) with strong zonal winds (with a mean of 13-14 $\mathrm{m} \mathrm{s}^{-1}$ ) extending from the western Caribbean to the Lesser Antilles at around $925 \mathrm{hPa}$. The CLLJ was obtained from Hidalgo et al. (2015) and consistently with Amador $(1998,2008)$, the index was composed by averaging the zonal wind speed at $925 \mathrm{hPa}$ from the NCEP/NCAR reanalysis over the region bounded by coordinates $75^{\circ} \mathrm{W}$ $85^{\circ} \mathrm{W}, 7.5^{\circ} \mathrm{N}-12.5^{\circ} \mathrm{N}$. The PDO index (1948-2013), which consists of the first principal component of monthly SST in the North Pacific, was obtained from ESRL-PSD-NOAA. The AMO (Enfield et al. 2001), which represents the smoothed SST variations in the North Atlantic, was also obtained from ESRL-PSD-NOAA. Alternatively, we included two composed indexes constructed using the difference and summation of the ENSO and TNA standardized index, as these indexes are known to be correlated with $\mathrm{P}$ and Tavg respectively in large parts of the region (Maldonado and Alfaro 2011; Maldonado et al. 2013; Enfield and Alfaro 1999).

\subsection{Climate projections using historical datasets}

A climate change application regarding the use of the $\mathrm{P}$ and Tavg high-resolution historical datasets in statistical downscaling is presented briefly. Monthly precipitation and average temperature projections (1979 to 2049) from fourteen General Circulation Model (GCM) runs from seven different models listed in Table S5 were used in a statistical downscaling procedure to produce estimates of these variables at $\sim 5 \mathrm{~km}$ resolution. The runs were selected from a pool of 107 runs from 48 models, by considering those ranked in top positions regarding their skill to reproduce basic regional climatological aspects, as shown in Hidalgo and Alfaro (2015). The statistical downscaling procedure to generate the future climate requires the historical high resolution Tavg and $\mathrm{P}$ datasets, and this is one of the reasons why a Tavg was needed to be produced. The statistical downscaling procedure is a modification of the Bias Correction and Spatial Disaggregation (BCSD) procedure (Wood et al. 2004). Details on the procedure can be found in Appendix J. 


\section{Results}

\subsection{Climatologies of Tavg and $P$}

The climatological values of the high resolution Tavg and P datasets for January and July are shown in Fig. 1. As expected, the resulting Tavg patterns are strongly influenced by elevation, although other factors such as distance to the coast may be also playing a role. The datasets also capture other realistic features. For example, seasonal Tavg contrasts are more accentuated

\section{Temperature}

a) January

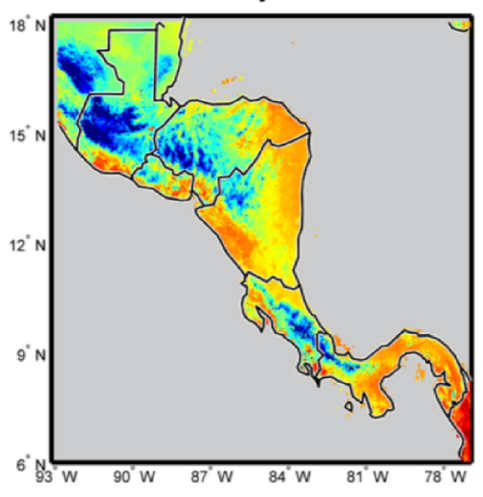

b) July

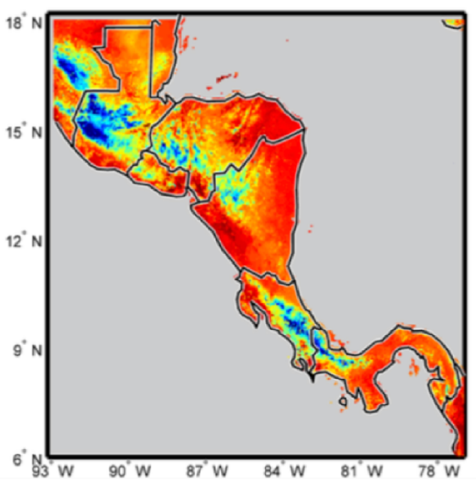

\section{5}

${ }^{\circ} \mathrm{C}$

25

\section{Precipitation}

c) January

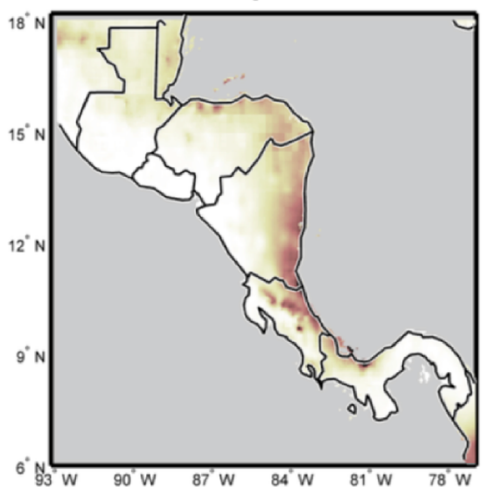

d) July

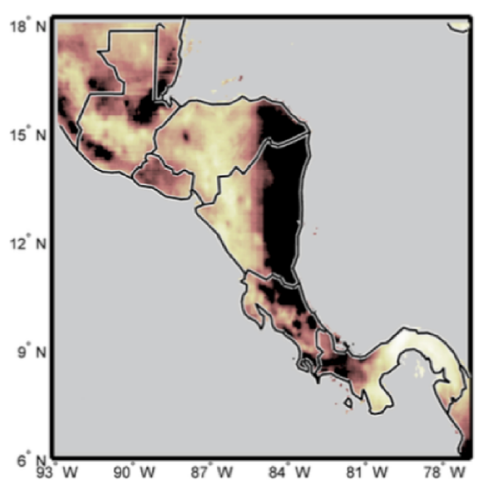

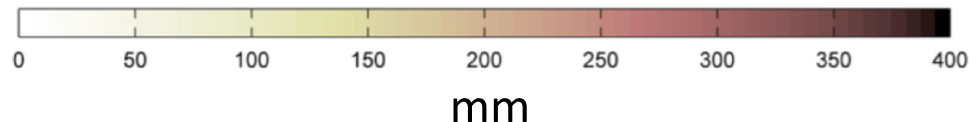

Fig. 1 January and July climate normals of surface temperature $\left({ }^{\circ} \mathrm{C}\right)$ and precipitation $\left(\mathrm{mm} \mathrm{month}{ }^{-1}\right)$. The period of the data is 1970-1999 
in the northern regions (higher latitudes) than in the southern regions (lower latitudes). This is particularly true for the continental regions in Guatemala. In the case of the $\mathrm{P}$ dataset, it captures realistically the seasonal contrasts over the year, in particular there is a skill in reproducing the differences between the Caribbean and Pacific slopes. The drier areas of the Central American Dry Corridor (Hidalgo et al. 2015), a region of relatively drier climatological conditions covering most of the Pacific slope of Guatemala, Honduras, El Salvador, Nicaragua and the north Pacific coast of Costa Rica can be identified in the precipitation normal patterns. Contrary to Tavg, the P patterns were not constructed based on topographic aspects and they do not present a marked elevation influence for all months of the year.

\subsection{Trends in Tavg and $P$}

Trends in annual Tavg were more consistent and statistically significant than trends in annual P (Fig. 2). Our results show that there are vast areas of the region that show significant Tavg trends (Fig. 2). Central America is warming up significantly in most of Guatemala, El Salvador and southern Mexico (northern part of the region), and also in a large part of Costa Rica and the Caribbean coast of Nicaragua. There are significant cooling trends in parts of Honduras and Panama. Notice that although the climatologies shown in Fig. 1 are influenced by topography, the Tavg trending patterns present less spatial heterogeneity and are not so much modulated by elevation.

Trends in $\mathrm{P}$ were generally non-significant. This lack of consistently strong $\mathrm{P}$ trends has been mentioned in other studies (Aguilar et al. 2005; Alexander et al. 2006). The P dataset suggests positive trends in the southern Caribbean coast of Costa Rica and smaller (but significant) positive trends in Guatemala, El Salvador and Panama. Drying trends are found mainly in the Central Pacific slope of Costa Rica and in a small part in the middle of Panama.

\subsection{Correlations of Tavg and $P$ datasets with climatic indices}

Consistently with previous studies (e.g. Waylen et al. 1996; Alfaro 2007b; Alfaro 2014), the ENSO signal in P is present in the Pacific slope of Central America (Fig. 3a), which results in drier (wetter) conditions during the warm (cold) phase of ENSO. The influence of this climatic feature is also widespread in Tavg across Central America (Fig. 3b). Similar results were obtained for TNA, as it correlates significantly with $\mathrm{P}$ in a large portion of the region (Fig. 3c), especially in the northern part (for latitudes above $10^{\circ} \mathrm{N}$ approximately), meaning that the northern part has a different Atlantic precipitation teleconnection than the southern part. Tavg is also significantly correlated with TNA, especially for latitudes north of the border between Costa Rica and Panama (Fig. 3d). It has been found in other studies that an index consisting of calculating the difference between the standardized values of ENSO indexes and TNA is a better predictor of precipitation in the region (Maldonado and Alfaro 2011; Maldonado et al. 2013; Enfield and Alfaro 1999). In fact, the ENSO index Niño3.4 is highly correlated with P in most of the region (Fig. 3e and Appendix F in Supplementary Material), suggesting that the SSTa contrast between the Pacific and the Caribbean/Atlantic is an excellent indicator of $\mathrm{P}$ in the region (see Appendix F in Supplementary Material). Conversely, the summation of the Niño3.4 index and TNA is highly correlated with Tavg in most of Central America, as it is seen in Fig. $3 \mathrm{f}$ and in the Supplementary Material. The CLLJ index presents significant correlations with most of the precipitation in the Pacific Coast of Central America, but presents weak correlations with Tavg. AMO presents strong and significant correlations with the first 
Fig. 2 Annual trends (19701999) of average temperature in ${ }^{\circ} \mathrm{C}$ $\mathrm{yr}^{-1}$ (top) and precipitation in $\mathrm{mm}$ $\mathrm{yr}^{-1}$ (bottom). Only significant trends at the $p=0.05$ level are shown (as colored regions)
a) Temperature (Tavg)

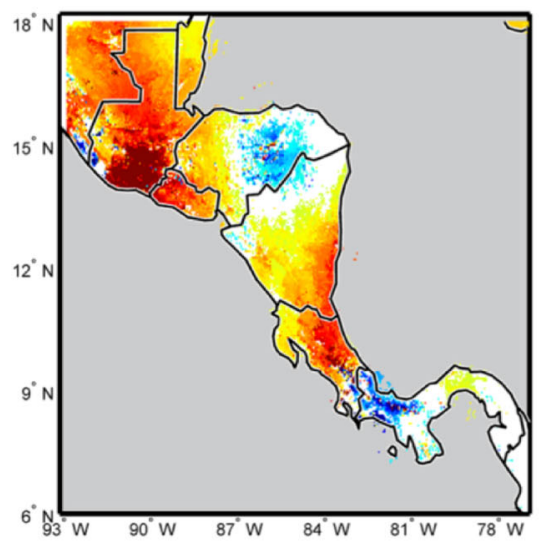

b) Precipitation (P)

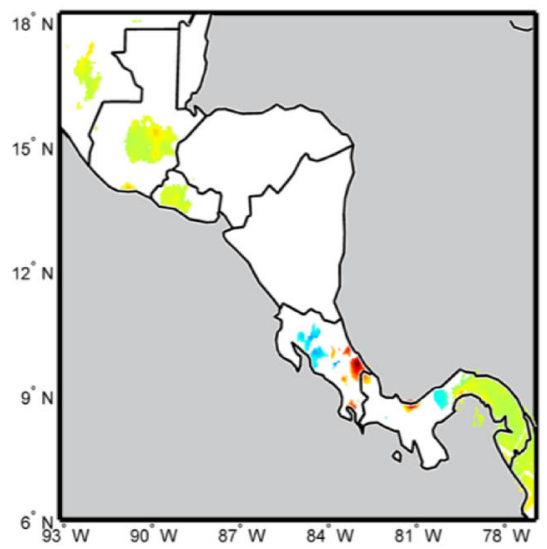

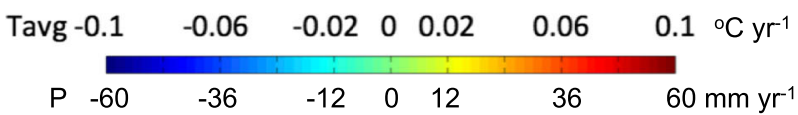

REOF of P and Tavg (Table S4, Supplementary Material), suggesting a multidecadal influence in the region. The PDO is also correlated significantly with one of the first three modes of $\mathrm{P}$ and Tavg, meaning that there is also a discernible effect on the climate variability of the region associated with this large-scale mechanism (Table S4, Supplementary Material).

\subsection{Rotated empirical orthogonal functions (REOFs)}

The REOFs analysis resulted in patterns difficult to attribute to a single large-scale process such as ENSO, AMO, PDO, CLLJ, TNA, or any one of the combined indexes (Table S4, Supplementary Material). For this reason, a CCA of the combined effects of $\mathrm{P}$ and Tavg is presented in the following sub-section, with the purpose of determining if the precursors of variability and trends can be identified more clearly. 
Fig. 3 Annual Spearman rank correlations between climate indexes and precipitation and temperature. The significant correlation at the $\mathrm{p}=0.05$ level is shown with a black line. The period of the data is 1970-1999
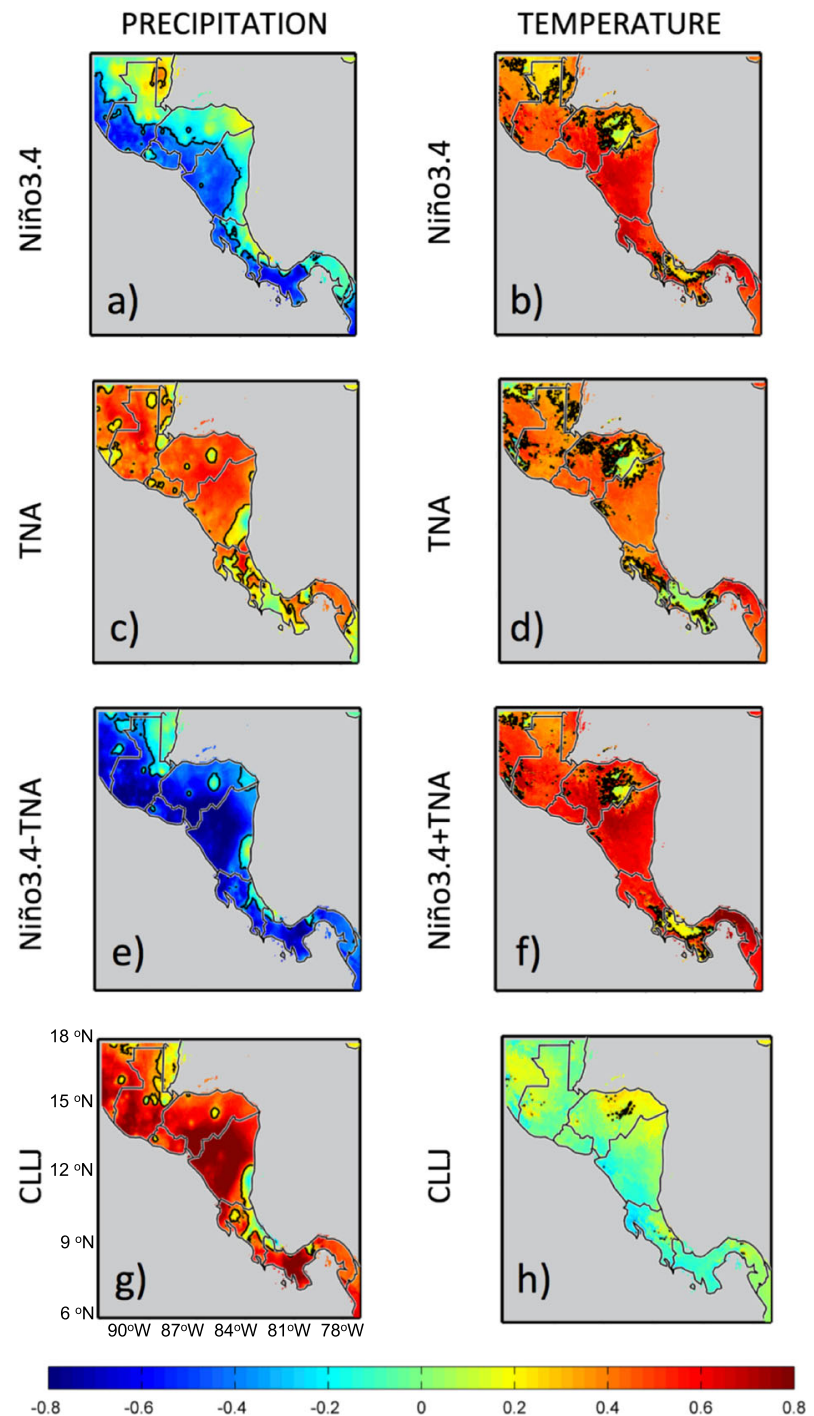

\subsection{Common precipitation and temperature signals}

In the same way as for REOF analysis, the resulting time series from the CCA called "scores" can be correlated back to the original gridded $\mathrm{P}$ and Tavg time-series to produce "loadings maps" (Figure S7). These loading maps are useful for determining the area of influence of each canonical pair, and therefore indicate which region of $\mathrm{P}$ is correlated with which region of Tavg, and additionally identifying the region of influence of the indexes with $\mathrm{P}$ and Tavg. The scores of the first three CCA modes are shown in Figure S8 of the Supplementary Material. The first canonical pair has a Spearman inter-correlation of $r=0.82(p<0.01)$, representing trends in P and Tavg (Figures S7 and S8). The second canonical pair has an inter-correlation of $0.54(\mathrm{p}<0.01)$. The annual Niño3.4 (the ENSO index) is correlated significantly with the 
second mode of $\mathrm{P}(0.72, \mathrm{p}<0.01)$ and with Tavg $(0.56, \mathrm{p}<0.01)$, suggesting that this CCA mode represents the common variability associated with ENSO. The CCA then allows us to better differentiate the ENSO signal from other sources of variability and also from trends than the individual REOF analysis. The $\mathrm{P}$ scores for the first mode are also significantly correlated with the PDO $(r=0.43, \mathrm{p}<0.01)$, and the Tavg scores are also significant correlated with this index $(r=0.55, \mathrm{p}<0.01)$. This is not surprising, as ENSO and PDO could be considered part of the same mechanism (Polade et al. 2013) and are significantly correlated (Table S2 of the Supplementary Material). The third mode has non-significant inter-correlation between the $\mathrm{P}$ and Tavg scores.

\subsection{Climate change projections at mid-century}

Precipitation and average temperature mean annual differences between a mid-century (20292049) and a baseline climate scenario (1979-1999) are presented in Fig. 4. The projected change in P suggests future drier conditions compared to the baseline scenario in the northern part of Central America and wetter conditions in the southern country of Panama. This pattern is consistent with a future southward displacement of the Inter-Tropical Convergence Zone (ITCZ) mentioned in other studies as a possible signature of climate change in the region (Rauscher et al. 2011; Hidalgo et al. 2013). The ITCZ is a region of high precipitation at the convergence of trade winds from the north and south hemispheres and it is a major contribution to the availability of moisture during the wet season in Central America. Large areas corresponding to the dry and wet differences in the north and south are significant at the $p=0.05$ level (Fig. 4a and $b$ ). The warming projections at mid-century are significant throughout the region, for both representative concentration pathways (rcps) selected (Fig. 4c and d).

\section{Discussion}

There is a natural response of temperature with elevation, usually identified as the "environmental lapse rate" (between $6.5-10{ }^{\circ} \mathrm{C} \mathrm{km}{ }^{-1}$ ). PRISM-like methods use variable lapse rates for each location generally between this range, which resulted in realistic monthly Tavg patterns. Precipitation spatial distribution responds more to the slope position relative to the wind, distance to the coast, local topography, and other remote drivers like the ones explained in Hidalgo et al. (2015).

The warming in the northern part of Central America, in particular in the Pacific coast, is consistent with other studies. The 1982-2005 trends are shown in Hidalgo et al. (2013) using CAMS data. The 1970-1999 warming trends in the northern and southern parts of Central America are also present in the CAMS dataset and in the CRUTEMP2 dataset. The cooling trends in Honduras are also partially captured by the TEMP2 dataset (not shown). Interestingly, the data from the NCEP/NCAR reanalysis only show significant Tavg trends (1970-1999) in a few grid-points of Central America. The ultimate reasons behind the lack of strong trends in the NCEP/NCAR reanalysis are unknown, but there could be related to spatial smoothing effects that may be affecting the trends, as the resolution of the reanalysis (around 1.89 degrees) is relatively coarse compared to the size of Central America. Note that a similar analysis that was performed using the 0.5-degree CRUTEMP2 dataset has some resemblance or consistency to this study (not shown). However, the novelty of this study is the detail features of the results, which can be obtained only when high-resolution data are available, which is particularly useful for identifying impacts at the fine scale. 


\section{a) Pdiff (rcp4.5)}

b) Pdiff (rcp8.5)

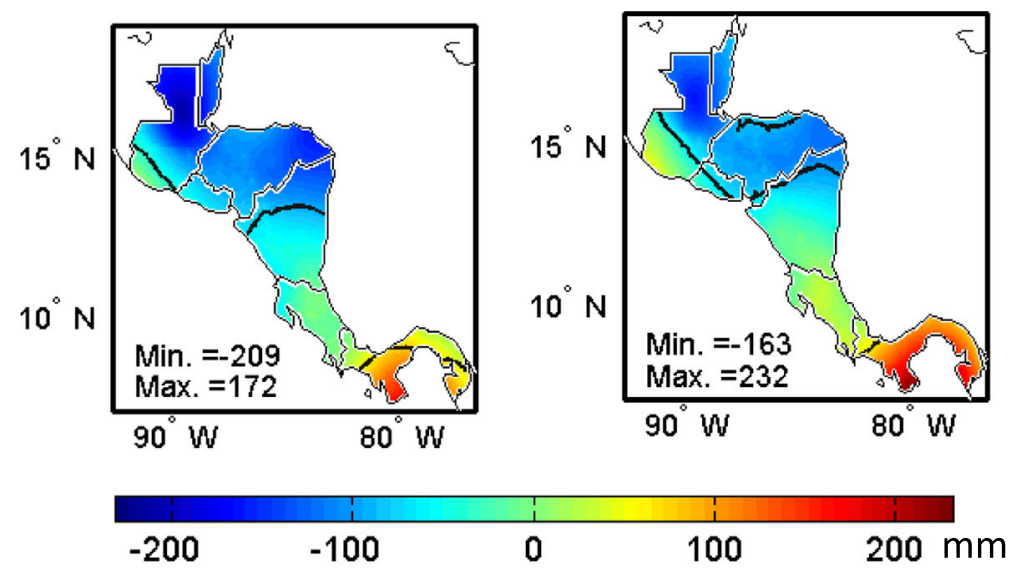

c) Tdiff (rcp4.5)

d) Tdiff (rcp8.5)

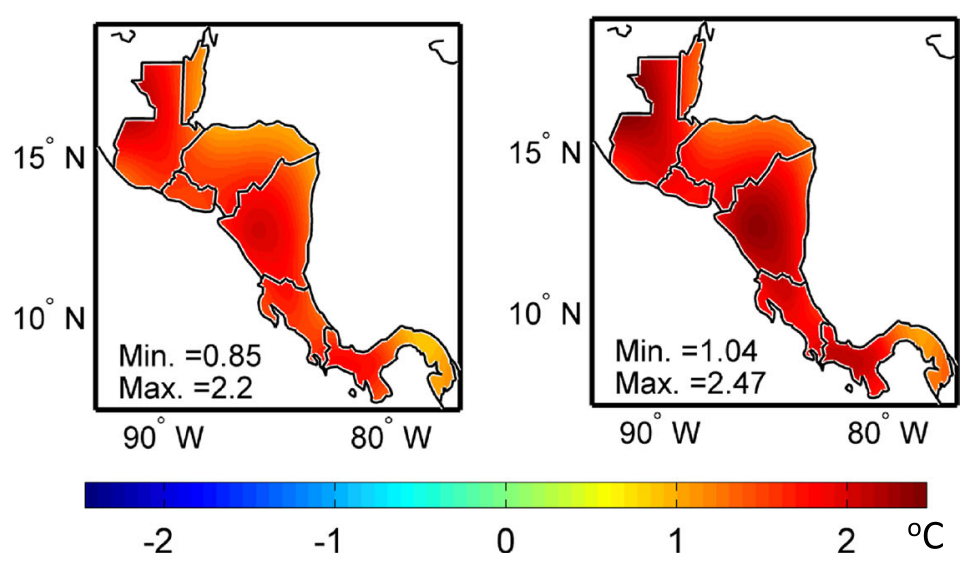

Fig. 4 Difference between mid-century (2029-2049) climate change and baseline (1979-1999) scenarios for annual total precipitation in $\mathrm{mm}(\mathbf{a}, \mathbf{b})$ and average annual temperature in ${ }^{\circ} \mathrm{C}(\mathbf{c}, \mathbf{d})$. For each variable two representative concentration pathways (rcp4.5 and rcp8.5) are shown. The dark contour in (a) and (b) represents the $\mathrm{p}=0.05$ level change in the mean. All changes in (c) and (d) are significant at the $\mathrm{p}=0.05$ level

Annual trends for precipitation were usually non-significant, in the datasets analyzed. This pattern is very common in Central America since most of the variability of the precipitation time series is allocated at interannual scales rather than in long-term trends Hidalgo León et al. 2015). Non-significant 1970-1999 trends for Central America are also widespread in the CHEN and the NCEP/NCAR reanalysis P dataset (not shown). This latter dataset only showed significant drying trends in southern Pacific coast of Costa Rica (not shown). Even with no significant changes in precipitation, warming trends in the region can still have severe consequences in the hydrology of the region, as increases in evapotranspiration can produce significant reductions in runoff and water availability (Hidalgo et al. 2013). 
The contrast in SST between the Pacific and Atlantic Ocean as a good indicator of precipitation in most of the Central American region was suggested by Maldonado and Alfaro (2011); Maldonado et al. (2013) and Enfield and Alfaro (1999) who attributed the correlations between SSTs and P to the strengthening or weakening of the trade winds. The strength of the rainfall response appears to depend on how SSTa in the tropical Atlantic and eastern Pacific combine. The strongest $P$ response occurs when the tropical Atlantic is in the configuration of a meridional dipole (anti-symmetric across the ITCZ) and the eastern tropical Pacific is of opposite sign to the tropical North Atlantic. When the tropical North Atlantic and tropical Pacific are of the same sign, the rainfall response is weaker, but the Tavg response is highly significant. Warmer (cooler) TNA along with a cooler (warmer) ENSO conditions are normally associated with weaker (stronger) trade winds across Central America (Enfield and Alfaro 1999). In fact, the difference index (Niño3.4 -TNA) is highly correlated with the CLLJ $(r=-0.74, p<0.01)$, and the index could be considered as an indicator of the strength of the trade winds. A suggestion of a linking mechanism between Pacific and Caribbean climate is found in Hidalgo et al. (2015). This reinforces the notion that not only the equatorial tropical Pacific is important for its influence on Central America's climate, but also the influence of the Caribbean climate plays an important role. For Tavg, the use of an index consisting of the summation of the Niño3.4 and TNA improves the correlations found for the individual indexes, suggesting that the agreement rather the contrast of SSTa in the Pacific and the Caribbean is a good indicator of Tavg in the region at annual scales (for reference the correlation of the summation index and CLLJ is weak and nonsignificant). Inter-correlation between the indexes is shown in table S2. Our results shows the highly significant predictability of the sign of annual $\mathrm{P}$ when the signs of the Pacific and Caribbean standardized SSTa differ, and a highly significant predictability of the sign of annual Tavg when they coincide (see Appendix F, Supplementary Material). The use of the information of the contrast between Pacific and Caribbean SSTa to predict seasonal precipitation has been studied before (e.g. Maldonado et al. 2013; Alfaro 2007b), but there are almost no studies linking temperature with this contrast (e.g. Alfaro 2007a; Alfaro 2000; Fallas-Lopéz and Alfaro 2014). Knowing which indexes modulate better temperature and precipitation could improve the outlooks (climate perspectives) of these variables and also the decision-making processes at different time and spatial scales.

The climate projections for Central America depict a significantly drier northern region and a wetter southern region at mid-century. This could aggravate the socioeconomic north-south differences in the future, as shown in Hidalgo and Alfaro (2012).

\section{Conclusions}

The analysis of the 1970-1999 climate variability of high-resolution P and Tavg datasets allowed us to identify large-scale atmospheric and oceanic signals in the data. This helped to understand various aspects of climatic variability with more spatial precision. This is particularly important in a region of complex topography such as the Central American isthmus. In addition, the annual results found here suggest the possibility of producing higher-resolution seasonal forecasts that are based on these large-scale climate precursors (e.g. Alfaro 2007a, 2007b; Maldonado and Alfaro 2011; Maldonado et al. 2013; Alfaro 2014; Fallas-López and Alfaro 2014) or to use the P and Tavg datasets to produce hydrological indexes to improve forecasts by including the hydrological "memory" of the land surface, with direct applications to the Regional Climate Outlook Forums in Central America (Donoso and Ramirez 2001; 
García-Solera and Ramírez 2012). The high-resolution Tavg dataset allowed a better characterization of the spatial patterns of annual trends in the region, and point to a widespread warming of Central America, with the exception of a few smaller areas that actually experienced cooling. The CCA analysis of the combined effect of $\mathrm{P}$ and Tavg allowed a better identification of the trending patterns and ENSO influence on the climate of Central America.

The contrast or the agreement of the Pacific and Caribbean/Atlantic oceans at annual time scales is an excellent indicator of $\mathrm{P}$ and Tavg over vast regions of Central America. Depending whether the oceanic masses present opposite or same sign anomalies there is the possibility of inferring the sign of the $\mathrm{P}$ or Tavg annual anomalies respectively.

There are many applications of the Tavg dataset produced here. One of the main aims in climate change studies is the quantification of observed trends and projections of hydrological variables (for example using General Circulation Models), with the purpose of detection (and attribution) of climate change, and of studies to estimate the climate change impacts in diverse sectors. For this, Tavg datasets are key as the meteorological $\mathrm{P}$ data alone is not sufficient to perform these studies. This is the case because the hydrological variables (such as runoff, soil moisture, evapotranspiration) are non-linearly related to $\mathrm{P}$ and also depend on temperature. The hydrological data (runoff, soil moisture, evapotranspiration) are also the basic variables needed to produce the climate change impact assessments in sectors such as hydropower, agriculture, social-economic, and others. In this sense, the high-resolution temperature dataset can be used as a complementary data to the CHIRPs precipitation dataset in climate change studies. In terms of projections, the dataset can also serve as the base historical data for statistical downscaling of General Circulation models (e.g. Wood et al. 2004; Maurer and Hidalgo 2008; Maurer et al. 2010), as it was shown in this study.

Acknowledgments This work was partially funded by the International Climate Initiative (ICI) of the German Federal Ministry for the Environment, Nature Conservation, Building and Nuclear Safety (BMUB), as part of the CASCADE project ('Ecosystem-based Adaptation for Smallholder Subsistence and Coffee Farming Communities in Central America'). The German Federal Ministry for the Environment, Nature Conservation, Building and Nuclear Safety (BMUB) supports this initiative on the basis of a decision adopted by the German Bundestag. Also by projects 805-A9-224, B4-227, A9-532 (supported by CSUCA-ASDI), B3-600, B6-143 (supported by Vice-presidency of Research at University of Costa Rica (UCR), CONICIT and MICITT), B0-810, B0-065, and A4-906 (CIGEFI-UCR, PESCTMA), from the Center for Geophysical Research (CIGEFI) of UCR. Thanks to the logistics support provided by the School of Physics of UCR. The authors thank Ricardo Herrera and Andrés Jiménez who formatted the data and collaborated in the calculation of some of the indexes. We thank The Betty and Gordon Moore Center for Science at Conservation International for providing funds for open access.

Open Access This article is distributed under the terms of the Creative Commons Attribution 4.0 International License (http://creativecommons.org/licenses/by/4.0/), which permits unrestricted use, distribution, and reproduction in any medium, provided you give appropriate credit to the original author(s) and the source, provide a link to the Creative Commons license, and indicate if changes were made.

\section{References}

Aguilar E et al. (2005) Changes in precipitation and temperature extremes in central America and northern South America, 1961-2003. J Geophys Res Atmos. doi:10.1029/2005JD006119

Alexander LV et al. (2006) Global observed changes in daily climate extremes of temperature and precipitation. J Geophys Res. doi:10.1029/2005JD006290

Alfaro EJ (2000) Response of air surface temperatures over central America to oceanic climate variability indices. Tópicos Meteorológicos y Oceanográficos 7:63-72 
Alfaro EJ (2007a) Predicción Climática de la Temperatura Superficial del Aire en Centroamérica. Ambientico 165:6-10

Alfaro EJ (2007b) Uso del análisis de correlación canónica para la predicción de la precipitación pluvial en Centroamérica. Revista Ingeniería y Competitividad 9:33-48

Alfaro EJ (2014) Caracterización del "veranillo" en dos cuencas de la vertiente del Pacífico de Costa Rica, América Central. Rev Biol Trop 62:1-15

Alfaro EJ, Soley FJ (2009) Descripción de dos métodos de rellenado de datos ausentes en series de tiempo meteorológicas. Revista de Matemáticas: Teoría y Aplicaciones 16:59-74

Amador JA (1998) A climatic feature of the tropical Americas: the trade wind easterly jet. Tópicos Meteorológicos y Oceanográficos 5:91-102

Amador JA (2008) The intra-Americas sea low-level jet, overview and future research. Ann of the N Y Acad of Sci 1146:153-188. doi:10.1196/annals.1446.012

Amador JA, Alfaro EJ, Lizano OG, Magaña VO (2006) Atmospheric forcing of the eastern tropical Pacific: a review. Prog Oceanogr 69:101-142. doi:10.1016/j.pocean.2006.03.007

Amador JA, Rivera ER, Durán-Quesada AM, Mora G, Sáenz F, Calderón B, Mora N (2016) The easternmost tropical Pacific. Part I: a climate review. Rev Biol Trop 64:S1-S22

Barnett TP, Pierce DW, Hidalgo HG, Bonfils C, Santer BD, Das T, Bala G, Wood A, Nazawa T, Mirin A, Cayan D, Dettinger M (2008) Human-induced changes in the hydrology of the western US. Science 319:10801083. doi:10.1126/science. 1152538

Bonfils C, Santer BD, Pierce DW, Hidalgo HG, Bala G, Das T, Barnett TP, Dettinger M, Cayan DR, Doutriaux C, Wood AW, Mirin A, Nozawa T (2008) Detection and attribution of temperature changes in the mountainous western United States. J of Clim 21:6404-6424. doi:10.1175/2008JCLI2397.1

Chen M, Xie P, Janowiak JE, Arkin PA (2002) Global land precipitation: a 50-yr monthly analysis based on gauge observations. J of Hydrol 3:249-266. doi:10.1175/1525-7541(2002)003<0249:GLPAYM>2.0.CO;2

Daly C, Neilson RP, Phillips DL (1994) A statistical-topographic model for mapping climatological precipitation over mountainous terrain. J of Appl Meteorol 33:140-158. doi:10.1175/1520-0450(1994) 033<0140:ASTMFM>2.0.CO;2

Daly C, Gibson WP, Taylor GH, Johnson GL, Pasteris P (2002) A knowledge-based approach to the statistical mapping of climate. Clim Res 22:99-113. doi:10.3354/cr022099

Daly C, Halbleib M, Smith JI, Gibson WP, Doggett MK, Taylor GH, Curtis J, Pasteris PA (2008) Physiographically-sensitive mapping of temperature and precipitation across the conterminous United States. Int J Climatol 28:2031-2064. doi:10.1002/joc.1688

Donoso M, Ramirez P (2001) Latin America and the Caribbean: report on the Climate Outlook Forums for Mesoamerica. In: Coping with the climate: a step Forward. Workshop Report "A multi-stakeholder review of Regional Climate Outlook Forums", October 16-20 (2000), Pretoria. Publication IRI-CW/01/1, pp 11-18

Enfield DB, Alfaro EJ (1999) The dependence of Caribbean rainfall on the interaction of the tropical Atlantic and Pacific oceans. J Clim 12:2093-2103. doi:10.1175/1520-0442(1999)012<2093:TDOCRO>2.0.CO;2

Enfield DB, Mestas AM, Mayer DA, Cid-Serrano L (1999) How ubiquitous is the dipole relationship in tropical Atlantic Sea surface temperatures? J of Geophys Res-Ocean 104:7841-7848. doi:10.1029/1998JC900109

Enfield DB, Mestas-Nunez AM, Trimble PJ (2001) The Atlantic multidecadal oscillation and its relationship to rainfall and river flows in the continental U.S. Geophys Res Lett 28:2077-2080. doi:10.1029/2000GL012745

Fallas-López B, Alfaro EJ (2014) Predicción estacional de las temperaturas máximas y mínimas en América Central. Tópicos Meteorológicos y Oceanográficos 13:5-26

Fan Y, van den Dool H (2008) A global monthly land surface air temperature analysis for 1948-present. J of Geophys Res. doi:10.1029/2007JD008470

García-Solera I, Ramírez P (2012) Central America's Seasonal Climate Outlook Forum. The Climate Services Partnership, 8 pp. Available online: http:/www.climate-services.org/sites/default/files/CRRH_Case_Study.pdf

Haan CT (1977) Statistical methods in hydrology. The Iowa State University Press / Ames, Iowa, p. 378

Hidalgo HG, Alfaro EJ (2012) Some physical and socio-economical aspects of climate change in central America. Prog Phys Geogr 36:379-399

Hidalgo HG, Alfaro EJ (2015) Skill of CMIP5 climate models in reproducing twentieth century basic climate features in central America. Int J Climatol. doi:10.1002/joc.4216

Hidalgo León HG, Herrero Madriz C, Alfaro Martínez EJ, Muñoz SG, Mora Sandí NP, Mora Alvarado DA, Chacón Salazar VH (2015) Urban Waters in Costa Rica. In: Urban Water Challenges in the Americas. A Perspective from the Academies of Sciences. Interamerican Network of Academies of Sciences. In press

Hidalgo HG, Das T, Dettinger MD, Cayan DR, Pierce DW, Barnett TP, Bala G, Mirin A, Wood AW, Bonfils C, Santer BD, Nozawa T (2009) Detection and attribution of streamflow timing changes to climate change in the western United States. J Clim 22:3838-3855. doi:10.1175/2009JCLI2470.1

Hidalgo HG, Amador JA, Alfaro EJ, Quesada B (2013) Hydrological climate change projections for central America. J of Hydrol 495:94-112. doi:10.1016/j.jhydrol.2013.05.004 
Hidalgo HG, Durán-Quesada AM, Amador JA, Alfaro EJ (2015) The Caribbean low level jet, the inter-tropical convergence zone and precipitation patterns in the intra Americas sea: a proposed dynamical mechanism. Geografiska Annaler, series a. Phys Geogr 97:41-59. doi:10.1111/geoa.1208

Imbach P, Molina L, Locatelli B, Roupsard O, Mahe G, Neilson R, Corrales L, Scholze M, Cialis P (2012) Modeling potential equilibrium states of vegetation and terrestrial water cycle of Mesoamerica under climate change scenarios. J Hydrometeorol 13:665-680. doi:10.1175/JHM-D-11-023.1

IPCC (2007) In: Parry M, Canziani O, Palutikof J, Van der Linden P, Hanson C (eds) Climate change 2007: impacts, adaptation and vulnerability. Cambridge University Press, UK, p. 841

Jones PD, Moberg A (2003) Hemispheric and large-scale surface air temperature variations: an extensive revision and an update to 2001. J of Clim 16:206-223. doi:10.1175/1520-0442(2003)016<0206:HALSSA >2.0.CO;2

Kalnay E, Kanamitsu M, Kistler R, Collins W, Deaven D, Gandin L, Iredell M, Saha S, White G, Woollen J, Zhu Y, Leetmaa A, Reynolds R (1996) The NCEP/NCAR 40-year reanalysis project. Bull Amer Meteor Soc 77: 437-471. doi:10.1175/1520-0477(1996)077<0437:TNYRP>2.0.CO;2

Maldonado T, Alfaro EJ (2011) Predicción estacional para ASO de eventos extremos y días con precipitación sobre las vertientes Pacífico y Caribe de América Central, utilizando análisis de correlación canónica. Revista Intersedes 13:78-108

Maldonado T, Alfaro EJ, Fallas B, Alvarado LF (2013) Seasonal prediction of extreme precipitation events and frequency of rainy days over Costa Rica, central America, using canonical correlation analysis. Adv in Geosci 33:41-52. doi:10.5194/adgeo-33-41-2013

Mantua NJ, Hare SR, Wallace JM, Francis RC (1997) A Pacific interdecadal climate oscillation with impacts on salmon production. Bull Amer Meteor Soc 78:1069-1079. doi:10.1175/1520-0477(1997)078<1069:APICOW>2.0.CO;2

Maurer EP, Hidalgo HG (2008) Utility of daily vs. monthly large-scale climate data: an intercomparison of two statistical downscaling methods. Hydrol Earth SystSci 12:551-563. doi:10.5194/hess-12-551-2008

Maurer EP, Adam JC, Wood AW (2009) Climate model based consensus on the hydrologic impacts of climate change to the Rio Lempa basin of central America. Hydrol Earth Syst Sci 13:183-194. doi:10.5194/hess-13183-2009

Maurer EP, Hidalgo HG, Das T, Dettinger MD, Cayan DR (2010) The utility of daily large-scale climate data in the assessment of climate change impacts on daily streamflow in California. Hydrol Earth Syst Sci 14:11251138. doi:10.5194/hess-14-1125-2010

Meehl GA, Arblaster JM, Tebaldi C (2007) Contributions of natural and anthropogenic forcing to changes in temperature extremes over the United States. Geophys Res Lett. doi:10.1029/2007GL030948

Navarra A, Simoncini (2010) A guide to empirical orthogonal functions for climate data analysis. Springer Dordrecht Heidelberg, London $151 \mathrm{pp}$

Pierce DW, Barnett TP, Hidalgo HG, Das T, Bonfils C, Sander B, Bala G, Dettinger M, Cayan D, Mirin A (2008) Attribution of declining western US snowpack to human effects. J Clim 21:6425-6444. doi:10.1175/ 2008JCLI2405.1

Polade SD, Gershunov A, Cayan DR, Dettinger MD, Pierce DW (2013) Natural climate variability and teleconnections to precipitation over the Pacific-north American region in CMIP3 and CMIP5 models. Geophys Res Lett. doi:10.1002/grl.50491

Rauscher SA, Kucharski F, Enfield DB (2011) The role of regional SST warming variations in the drying of Meso-America in future climate projections. J Clim 24:2003-2016. doi:10.1175/2010JCLI3536.1

Taylor MA, Alfaro EJ (2005) Climate of central america and the caribbean. In: Oliver JE (ed) Encyclopedia of world climatology. Netherlands: Springer, p 183-188

Waylen PR, Caviedes CN, Quesada ME (1996) Interannual variability of monthly precipitation in Costa Rica. J Clim 9:2606-2613

Wood AW, Leung LR, Sridhar V, Lettenmaier DP (2004) Hydrologic implications of dynamical and statistical approaches to downscaling climate model outputs. Clim Chang 62:189-216. doi:10.1023/B\%3ACLIM. $0000013685.99609 .9 \mathrm{e}$

Zebiak SE, Orlove B, Muñoz AG, Vaughan C, Hansen J, Troy T, Thomson MC, Lustig A, Garvin S (2014) Investigating el Niño-southern oscillation and society relationships. WIREs Clim Change 6:17-34. doi:10. $1002 /$ wcc. 294 